\title{
Why Adolescents with E - Wings Sarcoma Being Reluctant to Amputation?-A Study under the Phenomenological View
}

\author{
Guru Prasanna Lakshmi* \\ Department of Clinical Psychology, Sweekaar Academy of Rehabilitation Sciences, India
}

Submission: December 05, 2017; Published: December 19, 2017

*Corresponding author: Guru Prasanna Lakshmi, Department of Clinical Psychology, Sweekaar Academy of Rehabilitation Sciences, India, Email: guru.psychologist@gmail.com

\section{Abstract}

This study aimed to understand the implications and feelings associated during preoperative stage, with the process of amputation. Several perspectives through review of literature has allowed the knowledge to understand the phenomenon. In this study, the testimonies of 12 adolescents of male and female at preoperative stage of amputation, suffering with E-wings Sarcoma inclusive of upper and lower limb were analyzed. The interview of the adolescents, shown various perspectives through statements, by these sharing moments understood the concept from the perception of those who is experiencing it.

Keywords : Adolescence; Psychosocial Variables; Amputation

\section{Introduction}

\section{Concept of Adolescence}

Human life completes its journey through various stages and one of the most vital stage is adolescence. Adolescence is the period of transition, physically and psychologically from childhood to adulthood, and it starts with the puberty (Latin word meaning - Adult). Puberty was the beginning of adulthood itself, and not the beginning of the stage between childhood and adulthood.

It is a period when rapid physiological and psychological changes demand for new social roles to take place. The adolescents, due to these changes often face a number of crisis and dilemmas. It is the period when the child moves from dependency to autonomy. It demands significant adjustment to the physical and social changes. Erik Erikson called adolescence as "Psychosocial moratorium", in which people could try different roles to discover where they belonged in society. During this phase adolescents must integrate various roles into a consistent self- identity. Erikson believed that each stage of life is marked by a specific crisis or conflict between competing tendencies. If they fail to do so, they may experience confusion over who they are.
According to the psychologist G. Stanley Hall, adolescence as being a period of "storm and stress". During this period one really doesn't know where he or she stands. It is believed that this uncertainty about one's role causes many conflicts.

\section{Developmental tasks}

The problems that individuals typically face at different periods during their life. The developmental tasks present the vital problems which must be met and solved during the transition from childhood to adulthood.

Achieving new and more mature relations with age mates of both sexes
a. Achieving masculine or feminine social role.
b. Accepting one's physique and using the body effectively.
c. Achieving emotional independence of parents and other adults.

d. Developing intellectual skills and concepts necessary for civic competence.

e. Desiring and achieving socially responsible behavior. 
f. Acquiring a set of values and an ethical system as a guide to behavior.

\section{Gender roles}

Gender roles refer to the expectations concerning the roles males and females should perform and the way they should behave. The beliefs about the gender roles continue to influence us and our behavior throughout the life.

\section{Physical appearance and Body image}

Regardless of the timing of the physical changes that take place during adolescence, this is a period in which physical appearance commonly assumes paramount importance. Both girls and boys are known to spend hours concerned about their appearance, particularly in order to "fit in" with the norms of the group with whom they most identify. At the same time they wish to have their own unique style, and they may spend hours together in the bathroom to achieve this goal.

\section{Cognitive development}

The changes in how adolescents think, reason, and understand can be even more dramatic than their obvious physical challenges. They are now able to analyze situations logically, in terms of cause and effect, and to entertain hypothetical situations and use symbols, such as in metaphors, imaginatively (Piaget 1950). The higher level thinking allows them to think about the future, evaluate alternatives and set personal goals (Keating 1990).

\section{Moral development}

It refers to the development of a sense of values and ethical behavior. Adolescent's cognitive development, in part, lays the groundwork for moral reasoning, honesty, and pro-social behaviors such as helping, volunteerisms or caring for others (Eisenberg, Carlo, Murphy and Van court, 1995)

\section{Emotional development}

Emotional development during adolescence involves establishing a realistic and coherent sense of identity in the context of relating to others and learning to cope with stress and manage emotions (Santrock 2001) processes that are life-long issues for most people.

\section{Sense of Identity}

Identity refers to more than just how adolescents see themselves right now; it also includes what has been termed the "possible self "-what individuals they might become and who they would like to become (Markus \& Nurius 1986). Establishing a sense of identity has traditionally been thought of as the central task of adolescence (Erikson 1968). Identity includes 2 concepts.

A. Self- concept: The set of beliefs one has about oneself. One's attributes (eg; smart, tall), roles and goals (eg; occupation one wants to have when grown) and interests , values and beliefs (religious, political)

B. Self esteem: Evaluating how one feels about one's self concept. 'Global' self esteem refers to how much we like or approve of our perceived selves as a whole. 'Specific' self esteem refers to how much we feel about certain parts of ourselves.

Self - esteem develops uniquely for each adolescent, and there are many different trajectories of self - esteem possible over the course of adolescence. (Zimmerman, Copeland, Shope and Dielman 1997). Thus self- esteem low or high, may remain relatively stable during the period of adolescence, or may steadily improve or worsen.

\section{Methodological Course}

Phenomenology is a descriptive, rigorous science that is concerned with the essence of experiences [1]. It calls upon us to take up the qualitative course of existence again, to rediscover the global meaning of existing [2]. The phenomenological method seeks what transcends the empirical particularities of the phenomenon, with a view to understanding it [3].

The study was started to understand the phenomenon i.e. "Attitude towards an amputation" and its possible determinants was the goal of the study. The testimonies were taken from the 12 adolescents aged between 13 to 17 years comprising 7 male and 5 female diagnosed with E-Wings sarcoma. Details discussed in detail in following (Table 1)

Table 1:

\begin{tabular}{|c|c|c|}
\hline & Male & Female \\
\hline Gender & 7 & 5 \\
\hline Age & $13-17$ & $14-17$ \\
\hline \multirow{4}{*}{ Diagnosis } & 4 - lower & 3-lower \\
\hline & 3-upper & 2- upper limb \\
\hline & limb E-wing & E-wing \\
\hline & sarcoma & sarcoma \\
\hline Education & 8th- Intermediate & 9th-intermediate \\
\hline Domicile & Suburban - Urban & $\begin{array}{c}\text { Rural, Suburban and } \\
\text { urban }\end{array}$ \\
\hline $\begin{array}{l}\text { Socio economic } \\
\text { strata }\end{array}$ & $\begin{array}{l}\text { Lower middle to } \\
\text { Middle }\end{array}$ & $\begin{array}{l}\text { Lower middle to } \\
\text { middle }\end{array}$ \\
\hline
\end{tabular}

\section{Procedure}

During preoperative stage who were showing various psychological reactions, requested for collaboration in study to give their testimonies. The interview was scheduled a week before the amputation and It started with the questions - What are you preoccupied with? What does this amputation mean to you? Can you describe it to me? What making you to not prepared for the surgery? How do you perceive this situation? Initially, after taking testimonies started analyzing to understand the meaning of the content. Finally, these units were synthesized to arrive at the essence of the phenomenon.

This synthesis took the form of the construction of thematic categories [4]. Merleau-Ponty's philosophical thinking was 
used to support discourse analysis, as he is the philosopher of existence, of the body, and the phenomenologist of perception. I perceive and I am perceived through my body, as it is my vehicle of being-in-the-world and, this way, I do not have a body, but I am a body. The "own body" or the "lived body" is the one that, through the sensitive, exercises vital communication with the world, which is what I live and not what I think. The body is our means of having the world and it is through the body that one relates with others, with things, with the world itself, experiencing my own body [5]. The people experiencing helplessly, showed the relation between the body and the world is changed, and hence expressed their perceptions with various underlying factors.

\section{Determinants Influencing Psychosocial Response}

The determinants can be grouped into psychosocial variables; they are discussed in detail followed by the (Table 2)

Table 2:

\begin{tabular}{|ll|}
\hline \multicolumn{2}{|c|}{ Psycho Social Variables } \\
\hline Personal & \\
\hline 1. & Age \\
\hline 2. & Gender \\
\hline 3. & Domicile \\
\hline Physical & \\
\hline 1. & Pain \\
\hline 2. & Hospitalization \\
\hline 3. & Lack of opportunities \\
\hline Psychological Psychological reactions \\
\hline Medical factors Type of Amputation \\
\hline Social factors in cultural context Family support \\
\hline
\end{tabular}

\section{Age}

The degree of psychological difficulty associated with amputation, generally increases with the age. The physical changes signal a range of psychological changes, which manifest themselves thought adolescence varying significantly from person to person. Psychological changes generally include questioning of identity and achievement of an appropriate sex role, movement towards personal independence and social changes in which, the most important factor is peer group relations. To this challenging scenario, the chronicle illness like cancer is adding extra efforts in which the adolescent may feel physical discomfort and can result in poor image and lower self esteem.

Anxiety symptoms and depressive symptoms are more common in the younger age group which is consistent with study done by Singh et al. [6,7]. Dunn found that younger amputees were significantly more at risk of developing depression than older amputees on account of activity restriction [8].

(Adolescent client: “I don't want to be labeled as disabled, and teased by others")

\section{Gender}

According to many studies the concept of amputation was observed with a different light, among boys and girls.

According to the studies, person has to face tremendous body changes after amputation and also quality of life decreases after amputation [9]. The perception towards changes would be entirely different among two genders. Indian study on male and female adolescents concluded saying that the females are more conscious about their ideal body image [10]. One more study discussed that the Women were less likely to be successfully fitted with a prosthetic limb at discharge than men [11]. Shukla et al. [12] reported a male to female ratio of 17:1 [12]. Similar findings have also been reported by Cavanaugh et al. [13] where they reported $75 \%$ of patients were male [13]. Gender is a significant predictor of psychological Quality of life and social adjustment, with women having significantly poorer outcomes on this variable. This is consistent with the literature on psychosocial adjustment to amputation, where any gender differences observed have tended to favor males [14-16]. With regard to social adjustment, this variable taps into aspects of body image and public self-consciousness, which appear to be of greater significance to [17-19].

(Female client: “I won't look beautiful anymore, my boyfriend will leave me "....crying spells)

(Male client: "my ambition was to become a police officer... Silence "mother says males do not cry but I don't know how to stop" ....crying spells)

\section{Domicile}

The nature of exposure and the kind of information relating to the concerned area depends on the environmental support. Whether the person belongs to rural background or Urban or sub-urban, the lack of possibilities in exploring the ways to understand the concept from diagnosis to the treatment plays a big role. Lack of professionals of concerned area to deal with and the availability of properly trained is limited. This mainly hampers the people belongs to rural and sub-urban criteria. People experience the emotional morbidity to even inquire and get clarified due to various factors.

(Client from entirely rural background:

Female client aged 16, married: ("My spouse demanding divorce as I am going to be disabled with one leg, my in-law said we are not saint's to accept you. Spouse is getting ready for 2 nd marriage" ... crying spells)

\section{Physical}

\section{Pain}

Pain can be difficult to measure and even more difficult to treat because everyone experiences pain differently. There are varying types of pain and pain intensities, and some people experience pain for longer durations than others. Besides an 
alternative for pain relief, amputation is a procedure has to be done to maintain the life, for people with tumors. Even after considering the psychological and physical consequences, it provides a long term existence.

(Client: "I am ok with cancer because there are treatments to get cure, but not able to digest the word amputee, which is hurting much rather the tumor pain")

(Another Client: " Pain relief can be acquired by consuming tablets... pain being amputee is not bearable")

Here intention behind their words was to avoid dependencyi.e. for their daily activities, financially, not be able support in any of the sense. Being dependent was extremely painful and discouraging. They feel that they are going to be burden in all the ways which they don't want to be, but at the same time the process has to be followed.

\section{Hospitalization}

Patients see the hospitalization as frightening and inhuman They start to feel in a way of playing of sick role, where they are separate from their normal life, family members and permeated by tense and sad feelings, equally inhabited by the unknown persons to which he has to get interact any way.

(Client: "since 2 months I am in this room, feeling damn bored, wanted to go to home")

(One more Client: "My mom is only here with me, and father went to work. She is only taking care of everything. In home my younger siblings are crying for my mom and she also cries over the phone ... I feel helpless and waste")

(Another Client: "No full information regarding the diagnosis and the treatment, un known drugs, so many tests and some were repeated ...why no answers for the questions I hate being in the hospital")

\section{Lack of Opportunities}

Being in the hospital for a period of time leaving the regular life style/activities and has to adapt and adjust in new environment. Doctors or the professionals visit in timings and the rest of the day goes in waiting. Treatment is continuous, adolescents seek independence to do something but the cancer makes them dependence.

(Client: I feel lost in this ward, everything is lost, no college no friends, always in eager to know when will I get discharge).

(Another client: I am completely restricted to bed, daily with colorful injected bottles, so cannot move even for the washroom. Parents don't allow me to walk outside, sometimes I feel tired)

\section{Psychological Factors}

All though it s well recognized that the diagnosis of cancer and exhausting treatment are extremely stressful events and emotional burdens for the patient, it is only the last decade or two that the specific characteristic of psychosocial problems secondary to cancer have been studied in more detail [20].

\section{Psychological Reactions and Adjustment to Diagnosis and Treatment}

When doctor is enclosing information on cancer patient because of existential threat has to use series of adaptive defenses to withhold psychological stability. The very first encounter with a diagnosis of malignant disease arouses more intense emotional reactions than with any other disease. This leads to creating defense mechanisms with which doctors should be familiar and should acknowledge in therapeutic process. Usual accompanying psychological symptoms are fear of body image changes, disabilities, addictions and death [21].

Psychiatric/psychological problems that can usually be seen among oncology patients are primarily depressive disorder, adjustment disorder, posttraumatic stress disorder and others are anxiety disorders. Patients meets with number of other problems such as suicidal thoughts, results of lack of family and social support, personality disorders which causes problems in state of extreme stress, question of ability to make decisions, mourning, quality of life, spiritual and religious questions, etc [22]. Body image distortion and body image anxiety occur among some people who have amputation [18]

(Client: I can't imagine myself without hand, it will be clearly visible to everyone to give comment)

(Another client: I don't want to speak....silence)

(Other client: crying spells .....Don't know)

Public attitudes towards disability rather than the existence of impairments alone, negatively affect feelings of well-being among individuals with disabilities. Rates of major depressive disorder are reported to be as high as $34 \%$ to $35 \%$ for inpatient amputees reporting and $21 \%$ to $35 \%$ for outpatient amputees [23]. Meanwhile, the onset of a traumatic and sudden event such as limb loss has an enormous impact on an individual's body, mind and social world, therefore creating a psychological disequilibrium [24].

\section{Medical Factors}

\section{Type of Amputation}

Individuals with an amputation are faced with adapting to several losses and changes to their lifestyle, social interactions and identity [23]. The loss of an upper limb potentially has a greater impact than Lower limb, this is because people's hands and arms are not only particularly important functionally, they allow people to manipulate objects and carry out most of the activities of daily living, but socially as well [25]. Amputation of a limb has an extensive effect on people's lives, with people losing many physical functions and abilities that were once taken for 
granted [25]. Post-amputation jobs were generally more complex with a requirement for a higher level of general educational development and were physically less demanding [26,27]. These factors indicate that re-integrationmay be more difficult.

\section{Social Factors in Cultural Context}

Childhood is neither timeless nor universal, it is not determined only by age, or by biological and psychological factors. Rather childhood is understood by reference to particular cultural and social contexts and to particular periods in history. Childhood in Mexico is not the same as childhood in Madras or Madrid. The child-rearing environment is characterized by large families and high infant mortality- a heavy emphasis on parents' efforts to ensure the physical survival of their children means that parents must devote much of their time to economic and domestic activity, with many "parenting" tasks delegated to other people, often older children.

Western notions of childhood often place an emphasis on children's vulnerability and innocence, but again in other contexts this may be much less appropriate. Many child-rearing practices also reflect particular cultural contexts- in some contexts in Asia, mothers may be quite protective of their children, seeking to keep their infants quiet and contented, and as they grow up there may be an expectation of compliance and conformity, and an acceptance of adult authority, by contrast many American parents may encourage open, expressive, autonomous and assertive behavior and allow a pre-school child to take physical risks that would be unacceptable to many Asian mothers.

(Client: I feel alone in fighting my problems, because they don't understand my pain. Don' share anything)

(Client Family: Our child is already suffering, so we don't to make him more suffer by revealing about his condition.)

(One more client: After the surgery, who am I, I know will completely loose myself. Already lost my identity, being dependent for everything and it continues for the entire life as abandoned and criticized from/by others).

\section{Discussion}

The testimonies of 12 adolescents of male and female at preoperative stage of amputation, suffering with E-wings Sarcoma inclusive of upper and lower limb. During the pre operative stage, patients have ambiguous feelings. Ewing sarcoma is one angle where the term itself new and just generalized as using the term cancer with local terms such as (GADDA) in southern part of India. Most of the people were unaware with medical term, some of them expressed we don't understand. These really make them stand in chaos i.e. from understanding its severity to treatment approach.

Understanding the adolescent stage with chronic illness continue to be a challenge for the client and the professional.
Although the client and the family affirmed their agreement with surgery, they displayed an emotions of denial, distress, anger, helplessness, worthlessness, lost self, crying, pressed down to earth, playing a sick role and so on.... Losing a body part means altered existence, in their words - everything would be changed, new life with new label, adjusting with incompleteness body, readapt, relearn but the acceptance from the society will be questionable.

\section{Conclusion}

Beginning, as a researcher started to collect the data as a part of study to find out the factors associated with the reluctance towards amputation. But when tried empathetically to understand the meaning of the content, it's clearly suggested for the essential, more effective and complete performance of health professional's activities to provide complete humanitarian care.

\section{References}

1. Capalbo C (1984) Alternativas metodológicas de pesquisa. In: Seminário Nacional de Pesquisa em Enfermagem 3; Florianópolis, Brasil. Universidade de Santa Catarina, Florianópolis, Brasil, pp. 130157.

2. Merighi MAB (2003) Fenomenologia. In: Merighi MAB \& Praça N de S (Eds.), Abordagens teórico- metodológicas qualitativas: a vivência da mulher no período reprodutivo. Guanabara Koogan Rio de Janeiro (RJ), Brazil, p. 31-39.

3. Carvalho AS (1987) Metodologia da entrevista: uma abordagem fenomenológica. Editora Agir, Rio de Janeiro (RJ), Brazil.

4. Boemer MR (1994) A condução de estudos segundo a metodologia de Investigação fenomenológica. Rev Latinoam Enfermagem janeiro 2(1): 83-94.

5. Martins Fontes (1994) Merleau-Ponty M. Fenomenologia da Percepção. São Paulo (SP), Brazil.

6. Desmond DM, Shevlin M, Mac Lachlan M (2006) Dimensional analysis of the coping strategy indicator in a sample of elderly veterans with acquired limb amputations. Personality and Individual Differences 40(2): 249-259.

7. Singh R, Ripley D, Pentland B, Todd I, Hunter J, et al. (2009) Depression and anxiety symptoms after lower limb amputation: the rise and fall. Clinical rehabilitation 23(3): 281-286.

8. Dunn DS (1996) Well-being following amputation: Salutary effects of positive meaning, optimism, and control. Rehabilitation Psychology 41(4): 285-302.

9. Tejaswini Kulkarni, Deepali Hande, Kalpita U. Parab (2014) Body image and quality of life among individuals with lower limb amputation. Indian Journal of Basic and Applied Medical Research 3(3): 63-66.

10. Shah Hasmukh D, Shaikh Wasim A, Singh SK (2012) Are Indian Adolescent Girl Students More Conscious about their Body Image than their Colleague Boys? National Journal of Community Medicine 3(2): 344-347.

11. Rajiv singh, John hunter, Alister philip, Sarah Tyson (2009) Gender differences in amputation outcome. Journal of Disability and Rehabilitation pp. 122-125.

12. Shukla GD, Sahu SC, Tripathi RP, Gupta DK (1982) A psychiatric study of amputees. The British journal of psychiatry: the journal of mental science 141: 50-53. 
13. Cavanagh SR, Shin LM, Karamouz N, Rauch SL (2006) Psychiatric and emotional sequelae of surgical amputation. Psychosomatics 47(6) 459-64.

14. Horgan 0, Mac Lachlan M (2004) Psychosocial adjustment to lowerlimb amputation: a review. Disability and rehabilitation. 26(14-15): 837-850.

15. Phelps LF, Williams RM, Raichle KA, Turner AP, Ehde DM (2008) The importance of cognitive processing to adjustment in the 1st year following amputation. Rehabilitation Psychology 53(1): 28-38.

16. Kashani JH, Frank R, Kashani S, Wonderlich S, Reid J (1983) Depression among amputees. Journal of Clinical Psychiatry 44(7): 256-8.

17. Murray C (2010) Amputation, Prosthesis Use, and Phantom Limb Pain: Springer, USA. pp. 203.

18. Murray CD, Fox J (2002) Body image and prosthesis satisfaction in the lower limb amputee. Disability \& Rehabilitation 24(17): 925-931.

19. Furst L, Humphrey M (1983) Coping with the loss of a leg. Prosthetics and orthotics international 7(1): 152-156.

20. Grassi L, Gritti P, Rigatelli M, Gala C (2000) Psychosocial problems secondary to the cancer: an Italian multicentre survey of consultationliaison psychiatry in oncology. Italian Consultation-Liaison Group. Eur J Cancer 36(5): 579-585.

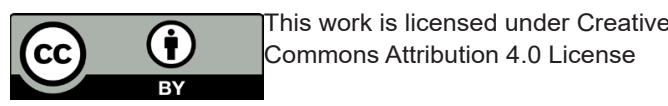

21. Tope DM, Ahles TA, Silberfarb PM (1993) Psycho-oncology: psychological well-being as one component of quality of life. Psychother Psychosom 60(3-4): 129-147.

22. Kadan Lottick NS, Vanderwerker LC, Block SD, Zhang B, Prigerson HG (2005) Psychiatric disorders and mental health service use in patients with advanced cancer. Cancer 104: 2872-2881.

23. Horgan O, Maclachlan M (2004) psychosocial adjustment to lower-limb amputation. Disability and Rehabilitation 26(14-15): 837-850.

24. Wegener ST, Mackenzie EJ, Ephraim P, Ehde D, Williams R (2009) SelfManagement Improves Outcomes in Persons With Limb Loss. Arch Phys Med Rehabil 90(3): 373-380

25. Davidson JH, Jones Cornet J, Cittarelli T (2001) Management of the multiple limb amputee. Disabil Rehabil 24(13): 688-699.

26. Saradjian A, Thompson RA, Datta Dipak (2008) The experience of men using an upper limb prosthesis following amputation: Positive coping and minimizing feeling different. Disabil Rehabil 30(11): 871-883.

27. Burger H, Maricek CRT (2007) Return to work after lower limb amputation. Disability and Rehabilitation 29(17): 1323-1329.

\section{Your next submission with Juniper Publishers will reach you the below assets}

- Quality Editorial service

- Swift Peer Review

- Reprints availability

- E-prints Service

- Manuscript Podcast for convenient understanding

- Global attainment for your research

- Manuscript accessibility in different formats

( Pdf, E-pub, Full Text, Audio)

- Unceasing customer service

Track the below URL for one-step submission https://juniperpublishers.com/online-submission.php 